\title{
Simetrías y asimetrías entre el procedimiento del sistema de oposición de marcas de Argentina y México
}

\author{
$* * * *$ \\ Elías Efrain San Miguel Medina \\ Universidad Nacional Autónoma de México \\ napoli.marado63@gmail.com
}

Recibido: 29 de octubre de 2021

Aceptado: 16 de diciembre de 2021

\section{Resumen}

El objetivo del presente trabajo es realizar un análisis comparativo que dimensione la importancia de la implementación del Sistema de Oposición de Marcas que proporciona la legislación de la República Argentina (Ley 22362 de Marcas y Designaciones) y su análoga de los Estados Unidos Mexicanos (Ley Federal de Protección a la Propiedad Industrial). Para llegar a las conclusiones se realizará un análisis comparativo de los sistemas de oposición que se implementan en Argentina y México. En este último, hay un sistema gris, mórbido, principalmente porque la autoridad en ningún momento plasma una manifestación respecto a la solicitud y a la contestación de la oposición debido a que no cumple el objetivo planteado en el decreto de la reforma implementada en la Ley Federal de Protección a la Propiedad Industrial, pues el oponente no puede tener respuesta a su oposición sino una vez que concluya el trámite de registro, por ende, lo coloca en un estado de incertidumbre jurídica, pues al ser la oposición parte del procedimiento administrativo de registro de marca, la autoridad debería dar una respuesta o comentarios después de la solicitud de la oposición y no solo cuando llegue al examen de fondo, lo que sí realiza son intervenciones de forma en el sentido de que si el usuario que promueve la solicitud de oposición se encuentra autorizado en el expediente para gestionar dicha petición, pero como tal no realiza algún comentario en relación a que si la oposición es admitida o no, en el mismo supuesto se encuentra el usuario solicitante si en el momento oportuno realiza la contestación a la 
oposición, la autoridad tampoco expresa alguna respuesta o declaración de fondo. En Argentina es un proceso más complejo, en el que en cada una de sus etapas se emiten comentarios.

Palabras clave: marcas, oposición.

\title{
Symmetries and Asymmetries Between the Procedure of the Trademark Opposition System of Argentina and Mexico
}

\begin{abstract}
The objective of this work is to carry out a comparative analysis that measures the importance of the implementation of the Trademark Opposition System provided by the legislation of the Republic of Argentina (Law 22362 on Trademarks and Designations) and its analogue in the United Mexican States (Federal Law for the Protection of Industrial Property). To reach the conclusions, a comparative analysis of the opposition systems implemented in Argentina and Mexico will be carried out. In Mexico there is a gray system, morbid mainly because the authority at no time expresses a manifestation regarding the request and the opposition's response, as a result of not fulfilling the objective set out in the decree of the reform implemented in the Federal Law of Protection of Industrial Property, since the opponent cannot have an answer to his opposition but once the registration process is concluded, therefore, it places him in a state of legal uncertainty, since the opposition is part of the administrative procedure for registration of trademark, the authority should give a response or comments after the opposition request, not only when it reaches the substantive examination, which if it performs are formal interventions in the sense that if the user who promotes the opposition request is is authorized in the file to manage said request, but as such does not make any comment in relation to whether the opposition is admitted year or not, in the same case the requesting user is found if at the appropriate moment the requesting party responds to the opposition, the authority does not express any response or substantive statement, while in Argentina it is a more complex process, where in each one of its stages will issue comments.
\end{abstract}

Key words: trademarks, opposition.

\section{Simetrias e assimetrias entre o procedimento do sistema de oposição de marcas da Argentina e do México.}

\section{Resumo}

O objetivo deste trabalho é realizar uma análise comparativa que mede a importância da implementação do Sistema de Oposição de Marcas previsto na legislação 
da República da Argentina (Lei 22.362 sobre Marcas e Designaçôes) e seu análogo nos Estados Unidos Mexicanos ( Lei Federal de Proteção à Propriedade Industrial). Para chegar às conclusóes, será realizada uma análise comparativa dos sistemas de oposição implantados na Argentina e no México. No México existe um sistema cinzento, mórbido principalmente porque a autoridade em nenhum momento se manifesta a respeito do pedido e da resposta da oposição, em decorrência do não cumprimento do objetivo previsto no decreto de reforma implementado na Lei Federal de Proteção da Propriedade Industrial, uma vez que o oponente não pode ter resposta à sua oposição, mas uma vez concluído o processo de registro, coloca-o, portanto, em estado de insegurança jurídica, uma vez que a oposição faz parte do procedimento administrativo de registro de marca, a autoridade deve dar resposta ou comentários após o pedido de oposição, não apenas quando chega ao exame substantivo, que se realizar são intervençóes formais no sentido de que se o utilizador que promove o pedido de oposição está autorizado no processo a gerir o referido pedido, mas, como tal, não faz qualquer comentário em relação ao fato de a oposição ser admitida ano ou não, no mesmo caso o usuário solicitante é encontrado se no momento apropriado o solicitante responde à oposição, a autoridade não expressa qualquer resposta ou declaração substantiva, enquanto na Argentina é um processo mais complexo, onde em cada uma de suas etapas emitirá comentários.

Palavras-chave: marca registrada, oposição.

Una marca es el conjunto de expectativas, recuerdos, historias y relaciones que, en conjunto, representan la decisión de un consumidor a elegir un producto o servicio a través de otro.

Seth Godin

\section{Nota introductoria}

La mayoría de la gente cree que el diseño es algo decorativo. Para mi, nada es más importante en el futuro que el diseño. El diseño es el alma de todo lo creado por el hombre.

Steve Jobs

El objetivo del presente trabajo es realizar un análisis comparativo que dimensione la importancia de la protección de las marcas, así como la utilidad de las diferentes herramientas legales que concede la legislación de la República Argentina (Ley 22362 de Marcas y De- 
signaciones) y su análoga en los Estados Unidos Mexicanos (Ley Federal de Protección a la Propiedad Industrial), en particular la implementación del Sistema de Oposición de Marcas para ambos países.

Para comprender la importancia de las marcas en el mercado global y, por ende, su protección, sería fundamental hacer referencia a la alegoría que ejecuta el maestro Otero, ${ }^{1}$ en la que cita:

Las marcas son en algún aspecto como las personas físicas, como los ciudadanos. Dependen de su propia fortaleza física, y del entorno en el que habitan.

Es así como un musculoso Rambo tendría más posibilidades relativas de sobrevivir en la jungla, en comparación con un delgado operador de computadora que usa anteojos y tiene alergia a las picaduras de insectos. Pero ese mismo técnico habilidoso se las ingeniaría mejor en un medio urbano, manejando aparatos e instrumentos, mientras Rambo se golpea contra los archivos y los escritorios transportando pilas de biblioratos.

Las marcas son fuertes o débiles en sí mismas, y lo son también en función en función del ámbito en el que les toca vivir (o sobrevivir) defendiéndose del embate de la competencia, o desafiando para provocarlo.

Así los comerciantes o los industriales son fuertes o débiles dueños de una marca deben protegerla y vigilarla en su origen y crianza, defenderla y promoverla en su desarrollo, consolidar su prestigio con la consistente calidad y reputación del producto o servicio al cual la aplican. (Otero Muñoz, 2011, pp. 422-423)

De lo anterior se puede entender la trascendencia que tienen las marcas para las empresas, ya sean emprendedores o gigantes trasnacionales. En efecto, es su herramienta fundamental, ya que es su imagen la que representa ante el público consumidor los productos y servicios que ofrecen en el mercado y, por ende, personifica la calidad o inclusive el estatus social que proporcionan dichos productos o servicios para el público consumidor en general. Por lo tanto,

1 Ignacio Otero Muñoz. Catedrático de la Facultad de Derecho de la Universidad Nacional Autónoma de México. 
una empresa puede invertir millones de dólares en crear la imagen corporativa que simbolizara su producto o servicios ante los consumidores primarios. En la actualidad, el valor de una empresa no solo se determina por la notoriedad que llegarán a tener ante los consumidores los bienes inmuebles o muebles que estén a su nombre o si se encuentran cotizando en el mercado de valores, sino también el valor que constituye su marca comercial como activo intangible.

Del ranking realizado por WPP y Kantar Millward Brown en 2021, ${ }^{2}$ en el que dan un listado del top 100 most de las marcas más valiosas del mundo, de manera enunciativa figuran en el top 10 las siguientes:

\begin{tabular}{l|l|l|c}
\hline Denominación & \multicolumn{1}{|c|}{ Categoría } & \multicolumn{1}{|c}{ País de origen } & $\begin{array}{c}\text { Valor en millones de } \\
\text { dólares }\end{array}$ \\
\hline Amazon & Comercio minorista & Estados Unidos de América & $\$ 415,855 \mathrm{M}$ \\
\hline Apple & Tecnología & Estados Unidos de América & $\$ 352,206 \mathrm{M}$ \\
\hline Microsoft & Tecnología & Estados Unidos de América & $\$ 326,544 \mathrm{M}$ \\
\hline Google & Tecnología & Estados Unidos de América & $\$ 323,601 \mathrm{M}$ \\
\hline Visa & Pagos & Estados Unidos de América & $\$ 186,809 \mathrm{M}$ \\
\hline Alibaba Group & Comercio minorista & República Popular China & $\$ 152,525 \mathrm{M}$ \\
\hline Tencent & Tecnología & República Popular China & $\$ 150,978 \mathrm{M}$ \\
\hline Facebook & Tecnología & Estados Unidos de América & $\$ 147,190 \mathrm{M}$ \\
\hline McDonald's & Comida rápida & Estados Unidos de América & $\$ 129,321 \mathrm{M}$ \\
\hline MasterCard & Pagos & Estados Unidos de América & $\$ 108,129 \mathrm{M}$ \\
\hline AT\&T & $\begin{array}{l}\text { Proveedores de } \\
\text { telecomunicaciones }\end{array}$ & Estados Unidos de América & $\$ 105,833 \mathrm{M}$ \\
\hline
\end{tabular}

En el listado en referencia es notable que resalta el campo de la tecnología sobre el resto, como también el aumento en la utilización de uso de datos y las tecnologías de intelligence-lead marketing como inteligencia artificial (IA) o realidad aumentada (AR), mezcladas con

2 Última revisión: 22 de abril de 2021. Disponible en: https://www.kantar. com/campaigns/brandz/global. 
orientación de marketing creativo. Aunado a lo anterior, la calidad en su producto y/o servicio ha permitido que varias marcas construyan un vínculo fuerte entre sus consumidores y brinden una relación más personalizada con experiencias gratificantes.

Por ende, las marcas tienen una principal relevancia no solo para los titulares de tales derechos, sino también para el consumidor primario que satisface sus necesidades básicas o secundarias al adquirir los productos y/o servicios que representan. Es así que, derivado del crecimiento industrial a niveles globales, resulta indispensable adecuar la legislación nacional e internacional para la correcta protección de estos valores intangibles que son las marcas. Es por ello que es fundamental la protección no solo en su proceso de registro (concesión/ otorgamiento), sino también en los ordenamientos legales correspondientes para la defensa de dichos derechos inmateriales. ${ }^{3}$ Tal es el caso de una adecuada implementación del procedimiento de oposición de registro marcario, que no solo facilitaría la protección de las marcas debidamente inscritas ante las autoridades administrativas competen-

3 Enneccerus (1935) señala que los bienes denominados "derechos sobre los bienes inmateriales" son: "Los productos del espíritu humano tienen en nuestra vida económica una significación autónoma, independiente de las cosas, en las cuales cobran su manifestación sensible. Una obra literaria o musical, un invento, una marca o un modelo, en virtud de las ideas o sentimientos a ella incorporados, se nos representan como algo independiente, que encierra un valor en sí mismo, dicho con otras palabras: es un bien adecuado para servir a los intereses humanos. A estos bienes los llamamos Bienes Inmateriales. El derecho moderno ha reconocido derechos a la exclusiva disposición sobre las obras del espíritu, principalmente a su aprovechamiento económico mediante su multiplicación, reproducción, ejecución, etc. Estos derechos se denominan derechos sobre bienes inmateriales, o bien, toda vez que pertenecen por de pronto al autor, derechos de autor. No cabe dudar de su naturaleza de derechos subjetivos privados dentro del margen de las disposiciones de las leyes especiales como lo demuestran entre otros atributos, su transmisibilidad inter vivos y mortis causa y su protección por acción privada. Además, son derechos patrimoniales. Pero tienen de común con otros derechos patrimoniales la circunstancia de no poder ser reducidos en todos los casos a un valor pecuniario. Mas no son derechos reales, pues el producto del espíritu, por ejemplo, la poesía, el invento, la sinfonía, no es una cosa. Constituyen más bien una clase independiente dentro de los derechos patrimoniales" (p. 1373). 
tes, ${ }^{4}$ sino que también brindaría un apoyo al sistema jurídico, ya que facilitaría que a las solicitudes de marcas que no son objeto de protección de acuerdo con la legislación aplicable les llegue la información y documentación necesarias para que estas no obtengan la concesión del Estado. Por esa razón, a futuro se evitaría el gasto económico y el desgaste humano que conlleva iniciar procedimientos de defensa, como son: acción declarativa de nulidad, acción declarativa de caducidad, acción declarativa de cancelación, juicio contencioso o inclusive una instancia constitucional, como es el juicio de amparo directo. De esta manera, se puede entender que si contamos con un sistema de oposición eficiente, se cumpliría de manera apropiada con el principio de economía procesal, ya que dicho punto acata el criterio indisoluble al que se refiere con la subsanación eficiente de la duración del debido proceso y el costo de la actividad jurisdiccional que recae en accionar este tipo medidas legales. Es por ello que es de tal importancia implementar de manera correcta un sistema de oposición al registro de marcas, recursos legales que son propios del sistema en México.

\section{Proceso de oposición para el registro de marcas ante el Instituto Nacional de la Propiedad Industrial (Argentina)}

Construir una buena marca puede llevar 30 años; destruirla, apenas 30 dias. $^{5}$

David D'Alessandro ${ }^{6}$

El término oposición fue acuñado por la Real Academia Española a partir de su origen en latín oppositio:

4 Instituto Nacional para la Propiedad Industrial, para Argentina, y el Instituto Mexicano de la Propiedad Industrial, para México.

5 El valor de una marca puede representar entre el 30\% y el $90 \%$ del valor de una compañía. Por eso, la construcción exitosa de la marcas es crucial. Y no solo eso, sino también conservarla, es decir, mantener la misma línea de calidad y de innovación por la cual los consumidores la eligen en lugar de a su competidor.

6 Presidente de John Hancock Mutual Life, Insurance, 6 de enero de 1999 (como se citó en Klein, 2002, p. 399). 
Del lat. oppositio, -ōnis.

1. f. Acción y efecto de oponer u oponerse.

2. f. Disposición de algunas cosas, de modo que estén unas enfrente de otras.

3. f. Contrariedad o antagonismo entre dos cosas. La oposición campo-ciudad.

4. f. Conjunto de pruebas selectivas en que los aspirantes a un puesto de trabajo, generalmente en la Administración pública, muestran su competencia, que es juzgada por un tribunal. U. m. en pl. con el mismo significado que en sing. Hizo oposiciones. Ganó las oposiciones.

5. f. Conjunto de grupos o partidos que en un país se oponen a la política del Gobierno o al poder establecido.

6. f. En los cuerpos legislativos, minoría que habitualmente impugna las actuaciones y propuestas del Gobierno.

7. f. Astron. Situación relativa de dos o más cuerpos celestes cuando tienen longitudes que difieren en dos ángulos rectos.

8. f. Ling. Relación distintiva que existe entre dos unidades del mismo nivel pertenecientes al mismo sistema lingüístico. ${ }^{7}$

Es decir que la etimología de la palabra oposición debe entenderse como una propuesta o forma de contraargumentar una situación o cosa en particular preexistente. Proponer una razón contra lo que otra persona dice, poner algo contra otra cosa para impedir su efecto, colocar algo frente a otra cosa, contradecir un designio.

Ahora bien, al referirnos directamente al ámbito de aplicación de la propiedad intelectual, el procedimiento en general de oposición le ofrece a cualquier tercero la posibilidad de impugnar el proceso de solicitud de una marca en el plazo que establezca la legislación aplicable. El usuario oponente debe alegar al menos uno de los argumentos motivo de la petición de oposición que estipula la Ley 22362 de Marcas y Designaciones (Argentina) o la Ley Federal de Protección a la Propiedad Industrial (México). Los procedimientos de oposición se encuentran vinculados directamente con los procesos de concesión de marcas, ya que al momento de que

7 Disponible en: https://dle.rae.es/oposici\%C3\%B3n?m=form. 
estos derechos de propiedad intelectual son publicados en el Boletín del INPI, ${ }^{8}$ cualquier tercero puede accionar esta forma de defensa a modo de invocaciones (Organización Mundial de la Propiedad Intelectual, 2011, p. 4).

La mayoría de los países de la Unión que ratificaron el Convenio de París 9 incluyen procedimientos de oposición en sus sistemas de concesión de marcas. Estos procesos le ofrecen a cualquier tercero la posibilidad de impugnar el otorgamiento de una marca en el plazo que establezca la ley en materia y durante su procedimiento de estudio o incluso después de su concesión. Por ello, el usuario oponente debe invocar o argumentar al menos uno de los motivos de oposición que estipula la legislación aplicable.

El procedimiento de oposición puede incoarse antes de que se conceda una marca; después de la concesión, se utilizan otros procedimientos administrativos, como el de nulidad o caducidad, o bien se recurre a la vía judicial, en la que se solicita la nulidad del registro marcario. Una de las metas principales del proceso de oposición es proporcionar un mecanismo sencillo, rápido y económico para que los usuarios utilicen el sistema de propiedad intelectual, que la autoridad competente pueda asegurar la eficacia y eficiencia de los procesos administrativos de protección de los derechos de marcas comerciales, al posibilitar la pronta rectificación de marcas que se hayan otorgado por un error humano del examinador de turno.

De forma ordinaria, los procesos de oposición tienen lugar en las oficinas de marcas y no en los tribunales. Esto ayuda directamente a los encargados del despacho de la oficina de marcas (INPI o IMPI) ${ }^{10}$ para avisarles o prevenirles antes de que comiencen con el estudio de examinación de dichos trámites cuando una solicitud es ingresa-

8 Disponible en: https://portaltramites.inpi.gob.ar/Boletines.

9 El Convenio de París, adoptado en 1883, se aplica a la propiedad industrial en su acepción más amplia, con inclusión de las patentes, marcas, dibujos y modelos industriales, modelos de utilidad, marcas de servicio, nombres comerciales, indicaciones geográficas y la represión de la competencia desleal. Este acuerdo internacional fue el primer paso importante para ayudar a los creadores a proteger sus obras intelectuales en otros países.

10 Disponible en: https://www.gob.mx/impi/acciones-y-programas/servicios-que-ofrece-el-impi y https:/www.argentina.gob.ar/inpi. 
da de mala fe o por desconocimiento sobre el funcionamiento del proceso de registro de marcas comerciales, ya que muchos usuarios (sin asesorarse legamente) solicitan las marcas sin previamente haber realizado una búsqueda de antecedentes. En algunos despachos de oficinas de marcas se gestionan dichas peticiones ante un órgano especial encargado de dirimirlos. Con frecuencia, el procedimiento de oposición de una marca se inicia una vez que se ha finalizado prósperamente el examen de forma de dicha solicitud. La oficina competente hace pública la solicitud de la marca y estipula un plazo legal para iniciar un procedimiento de oposición a ese expediente. Es ahí cuando el usuario oponente deberá argumentar o alegar los motivos de su solicitud de oposición y presentar las pruebas correspondientes (aunado el pago de los derechos, tasas o tarifas correspondientes). $\mathrm{Si}$ durante el plazo establecido no se inicia un procedimiento administrativo de oposición, se procederá al otorgamiento de la marca, según sea el caso. En el momento en el que se empieza un procedimiento de oposición se notificará de ello al solicitante de la marca objeto de la oposición para comunicarle los motivos de la oposición y las pruebas exhibidas. El usuario solicitante podrá dar contestación a la oposición del oponente de conformidad con lo establecido por la legislación aplicable y formular observaciones en el plazo fijado. De la misma forma, de acuerdo con lo estipulado en la ley en materia, el usuario oponente podrá responder a las observaciones del usuario solicitante (etapa de alegatos). En el proceso argentino, los alegatos se presentan al final del procedimiento o incidente de oposición "ratificada"; cuando las partes presentaron sus escritos, ofrecieron o produjeron las pruebas necesarias, el INPI les sugiere a las partes presentar los alegatos finales antes de emitir su decisión.

Después de las alegaciones presentadas por el usuario oponente y el usuario solicitante, el examinador de la autoridad administrativa $\mathrm{u}$ otra persona competente para solventar procedimientos de oposición en el marco de la legislación aplicable decidirán si debe o no concederse la marca.

Los procedimientos de oposición posteriores a la concesión son los que se interpolan cuando la marca ya ha sido concedida. Después de que se publica la concesión, puede comenzar un procedimiento de oposición y, asimismo, adjuntarse pruebas en el plazo 
previsto en la ley en materia. Al igual que en el caso de la oposición preliminar a la concesión, se notificará de ello al titular de la marca y se le dará la posibilidad de cumplir los requisitos determinados por la legislación aplicable y de formular observaciones en un determinado plazo.

En lo dispuesto en la legislación en materia, el oponente tendrá la posibilidad de responder a las observaciones del titular. Después de los alegatos presentados por el oponente y el usuario solicitante, el examinador o la persona competente para solventar dichos procedimientos de oposición en el marco de la legislación aplicable decidirá si se mantiene o se revoca la marca de que se trate. Además de los procedimientos de oposición, los sistemas nacionales de marcas pueden ofrecer a las terceras partes la oportunidad de oponerse al registro o concesión de una marca a través de procedimientos administrativos de nulidad o cancelación. Estos procedimientos se gestionarán después de que la marca ha sido concedida. Se pueden realizar en la oficina de marcas, o, en algunos casos, ante un tribunal, y permiten alegar motivos absolutos de denegación y motivos relativos de denegación. En los sistemas que facilitan ambas opciones -tanto procedimientos de oposición como de nulidad o cancelación- pueden hallarse semejanzas en lo que se refiere a los motivos de admisión de oposición y formas de promover las pruebas, pero dichos procedimientos tienen distintos objetivos: el sistema de oposición tiene una finalidad preventiva y los otros resarcen algún error u omisión de la autoridad competente.

En lo que respecta al proceso de oposición al registro de marcas en la Argentina, la mayoría de los estudios jurídicos que son consultados por los usuarios que estiman que les están violentando los derechos de su marca registrada previamente, se les sugiere a sus clientes presentar una acción de cese de uso por oposición en caso de que la solicitud de un tercero sea confundible con una previamente registrada. Esta es una forma extrajudicial para la solución de dicho conflicto y, por ende, se llega a una mediación sin necesidad de accionar el sistema legal correspondiente.

Ahora bien, en caso de que no se llegue a un acuerdo, se puede iniciar una solicitud de oposición al registro de marca que esté en trámite siempre y cuando se encuentre dentro de los treinta días después de 
su publicación en el Boletín. Previo a la reforma de la Ley 27444 de Simplificación y Desburocratización para el Desarrollo Productivo de la Nación a la reforma publicada en el Boletín de Marcas del Instituto Nacional de la Propiedad Industrial, de fecha 18 de julio de $2018,{ }^{11}$ se entendía que cualquier usuario podía oponerse a una solicitud de marca, de forma online o física, pagando el arancel correspondiente y poniendo como argumento dos párrafos: "Técnicamente se estila por ser confundible a las marcas de mi titularidad [...] Resol. No ......., Me reservo el derecho de ampliar fundamentos oportunamente [...]". Pero el fundamento de estas fórmulas se ubica en el artículo 4 de la Ley 22362, que exige interés legítimo. El desafortunado solicitante que recibía la oposición tenía que andar persiguiendo al oponente para negociar el levantamiento de la oposición, ofreciéndole un acuerdo de no competencia. Si no lograba levantar la oposición de buena manera, tenía que iniciar un juicio; en caso de cumplimentarse un plazo extenso, se declaraba el abandono. Luego de la reforma de la ley de mediación, se incorporó la necesidad de iniciar el procedimiento de mediación en la Ciudad Autónoma de Buenos Aires (CABA) para evitar la declaración de abandono y dejar expedita la vía judicial, por ello, se buscaba que un juez dictaminara que la oposición era infundada y obligara al INPI a concederle la marca al oponente (lo cual insume más de tres años y un segundo pago del arancel que compete en costos para el pobre solicitante). A esto habría que agregarle la cuestión federal que tanto México como Argentina comparten. En el caso de Argentina, al estar regulado el procedimiento marcario por la Ley de Procedimientos Administrativos federal y su decreto reglamentario, se fija competencia en CABA. Este fue siempre un problema para los solicitantes que no residen en esta ciudad. El hecho de tener que ir a litigar a la capital insume problemas temporales y económicos adicionales. Lamentablemente, el panorama no cambió con la reforma, ya que, en última instancia, se debe interponer un recurso directo en la Cámara Federal con sede en CABA ante una resolución del INPI que declare fundada una oposición.

11 INPI, Noticias, Resolución P-183: Resolución de Oposiciones. Disponible en: http://www.inpi.gob.ar/noticias/resolucion-p-183-resolucion-de-oposiciones. 
De esta situación, con el anterior sistema de oposiciones se beneficiaba a los usuarios con mayor capacidad financiera para afrontar los gastos adicionales del proceso de oposición, en especial si se debía concurrir a mediación previa o recurrir a la vía judicial, lo que obstaculizaba el acceso a una resolución barata y expeditiva a particulares, emprendedores o pymes.

Ahora bien, con la adhesión a la Ley 22362 de Marcas y Designaciones y las modificaciones introducidas por la Ley 27444 de Simplificación y Desburocratización para el Desarrollo Productivo ${ }^{12}$ se presentan las siguientes alternativas:

a. Si la marca del usuario oponente tuviera un alto grado de similitud con la que el usuario solicitante esté requiriendo su registro y protegiera los mismos productos o servicios, sería recomendable intentar llegar a un acuerdo para que el oponente no ratifique la oposición.

b. Si la marca del usuario oponente no tuviera un alto grado de similitud con la del usuario solicitante o no protegiera los mismos productos o servicios, lo recomendable sería no aceptar ninguna petición del oponente y dejar que avance a la siguiente instancia.

En el caso de oposiciones infundadas, lo más probable es que el oponente no avance a la siguiente instancia o, si lo hiciera, el INPI rechazaría la oposición. En el caso de que el oponente no ofrezca ningún acuerdo ni ratifique la oposición, el INPI la tendrá por no presentada y la considerará un simple llamado de atención, con lo cual, en esta instancia, la carga de instar el procedimiento recaerá en el oponente.

De las adhesiones en referencia ahora se entiende que el usuario que quiera ejercer su derecho a oposición a una solicitud de marca podrá seguir iniciando la oposición de manera online o física, pagando el arancel correspondiente y poniendo dos párrafos de argumentos, pero luego, el INPI le correrá traslado y le requerirá que para mantener esa oposición tiene que presentar un escrito fundado

12 Instituto Nacional de la Propiedad Industrial, Noticias, Comunicación Oficial. Disponible en: http://www.inpi.gob.ar/noticias/resolucion-p-183-resolucion-de-oposiciones. 
con argumentos y adjuntar pruebas, o para ampliar los fundamentos de oposición, y para ello se debe hacer un segundo pago de arancel, siempre y cuando esté dentro del pazo de quince días. Si no hiciera el pago, se tendrá por abandonada su oposición. Si lo hace, INPI le correrá traslado al solicitante, el cual puede presentar defensa sin necesidad de pagar tasas al INPI. A partir de ello, se dará apertura a una etapa de prueba para que en un plazo de cuarenta días ambas partes aleguen los documentos necesarios para respaldar su dicho. Luego, el INPI tendrá facultad para decidir quién tiene mejores argumentos, si el oponente o el solicitante, y emitirá una resolución en ese sentido, para luego aceptar o denegar la solicitud de marca. Todo, en plazos muy cortos, o sea, ahora se le hace mucho más difícil a los que quieran oponerse sin fundamentos, y mucho más fácil defenderse al que recibe una oposición. Asimismo, la resolución final del INPI puede ser recurrible vía judicial.

De lo anterior podemos entender que con las reformas hechas a la ley que nos compete lograron en lo particular adecuar un sistema de oposición más eficiente y eficaz, cumpliendo con el objetivo principal del decreto de dicha reforma, que es la de dotar de seguridad jurídica a las partes (oponente y solicitante) al momento de que el examinador del INPI efectúe las correspondientes manifestaciones de fondo durante la etapa de la solicitud y contestación de la oposición y no al final del procedimiento de registro de marcas (pasando la etapa de examen de fondo). De todos modos, en la práctica, el panorama no es tan optimista. El INPI no cuenta con los recursos necesarios para adaptarse a las reformas y a las nuevas facultades asignadas mediante la Ley 27444. Mucho tiempo después de la reforma, el INPI empezó lentamente a resolver oposiciones. Estas resoluciones tardan en emitirse, por lo que se generó una suerte de cuello de botella en muchos trámites. Asimismo, la pandemia agravo la situación.

Es así que con la implementación del Sistema de Oposición de Marcas, cualquier tercero puede apoyar al examinador del INPI para que durante el proceso de estudio de una solicitud de marca que se encuentre en trámite se apoye en integrar los elementos necesarios en el supuesto de que esta se considere como ilegal o no registrable de conformidad con la ley en la materia. Asimismo, si la solicitud de oposición no cumple con los requisitos de la ley, puede 
ser declarada no procedente por la autoridad facultada, como en el caso Mobel: ${ }^{13}$

Antecedente: Verónica Farías solicitó una marca bajo su nombre para proteger productos de la clase 20 internacional. A este registro se opuso Bernardo Nainsztein por entender que existía similitud en grado de confusión de su registro marcario STUDIO MOBEL, ya que el nombre era el mismo del usuario solicitante, pero en su tipo denominativa, y el registro marcario de Nainsztein era en su tipo mixto (denominación y diseńo), además donde las mismas marcas comparten productos idénticos para la clase internacional 20. Con esta solicitud de oposición se declaró fundada la oposición por considerar que corrían un alto riesgo de confusión.

Por lo expuesto, la autoridad administrativa, en el pasado 16 de mayo del 2021, resuelve en proceder con la oposición fundada del titular de la marca STUDIO MOBEL, C. Bernardo Nainsztein, declarando no procedente la solicitud de marca MOBEL con número de acta 3420131 a favor de la C. Verónica Farías, por una clara y evidente similitud en grado de confusión entre ambos signos distintivos; el usuario solicitante durante este proceso de oposición estuvo en la posibilidad de iniciar la defensa correspondiente, en relación a dar contestación a la oposición del C. Bernardo Nainsztein directamente ante INPI y no por medio de un recurso en vía judicial pero como la autoridad lo determinó existe una clara semejanza en grado de confusión por lo que infringe los derechos marcarios del titular de la marca STUDIO MOBEL.

Conclusión: en este caso podemos comprobar cómo estaba implementado el Sistema de Oposición antes de las reformas introducidas por la Ley 27444 de Simplificación y Desburocratización

13 Boletín de Marcas N 5156 - 09 de Junio de 2021 | Notificación en Procedimiento Resolución de Oposiciones (Ar. $9^{\circ}$ Resolución I.N.P.I. N P-183/18) "Caso Mobel". En la solicitud de marca número de Acta 3420131, para la clase internacional 20, solicitada por FARÍAS VERÓNICA, con oposición de NAINSZTEIN, BERNARDO, número de registro previo 86757, Estado: denegada, en la que la autoridad emitió la resolución de Oposición Número IF-2021-48828120-APN-DNM\#INPI. 
para el Desarrollo Productivo, ya que el solicitante que recibía una oposición solamente tenía como defensa una vía judicial. Otras de las innovaciones efectuadas por la implementación de las reformas de 2018 es darle al usuario solicitante la posibilidad de defenderse dentro del mismo sistema y no después de su finalización.

De esta manera, para los solicitantes de Argentina que tengan actualmente oposiciones recibidas lo recomendable es adherirse a este nuevo sistema para que, de manera más eficiente, puedan iniciar una defensa idónea para hacer las declaraciones pertinentes y así se dé una contestación conveniente a la oposición recibida por el oponente, en lugar de iniciar el dilatado y tortuoso camino para que el oponente levante la oposición interpuesta. De la misma forma, algo peculiar de mencionar en este caso es que ya habiendo un registro con la marca MOBEL (tipo mixta) y posteriormente la presentación de la marca MOBEL (como denominativa) es quién se hace cargo de las costas generadas, porque resulta evidente que el INPI no va a conceder una marca igual o similar a otra concedida. Entonces, una inquietud que se podría plantear es si debería el solicitante afrontar las costas del incidente de oposición al ser evidente que una solicitud con el mismo nombre no iba a prosperar, más allá de que una marca sea del tipo denominativa y la otra mixta. En el caso de México, han existido casos en los que la autoridad administrativa competente ha concedido registros con diseños (logotipos) y/o nombres muy parecidos o hasta idénticos que ya se habían registrado y con un titular totalmente distinto al del registro previo (sin presentar el consentimiento expreso), es por ello que resulta fundamental la buena praxis de dicho Sistema de Oposición para evitar estos errores humanos.

\section{Sistema de oposición en el procedimiento administrativo para el registro de marcas ante el Instituto Mexicano de la Propiedad Industrial}

El Instituto Mexicano de la Propiedad Industrial implementó de forma oficial en agosto de 2016 el Sistema de Oposición de Marcas, a través del cual se le permite a cualquier tercero ingresar su solicitud de oposición, siempre que considere que la marca que ha sido pu- 
blicada en la Gaceta del IMPI ${ }^{14}$ no merece ser concedida a su solicitante y que proporcione los fundamentos suficientes para demostrar que dicha solicitud de marca se configura en alguno o algunos de los impedimentos que mencionaba la abolida Ley de la Propiedad Industrial ${ }^{15}$ en su articulado 90; la mayoría de esos impedimentos se encuentran en la vigente Ley Federal de Protección a la Propiedad Industrial). ${ }^{16}$

Con este sistema, el IMPI le concede a cualquier usuario la oportunidad de manifestar su interés o descontento por el otorgamiento de alguna solicitud de marca que se encuentre en trámite, inclusive si esta se puede encuadrar en algunos de los supuestos de las causales de no registrabilidad, Esta situación se da en paralelo al procedimiento de registro de dicha solicitud, sencillamente retrasando ese proceso algunas semanas, ya que el Instituto, en una de las etapas del sistema de oposición, permite alegatos de ambas partes para que manifiesten lo que su derecho concierten.

El Sistema de Oposición comienza cuando el IMPI publica la solicitud de marca en la Gaceta. El usuario oponente contará con treinta días corridos para presentar su escrito de solicitud de oposición, en el que argumenta y cita su impedimento al registro de dicha solicitud. Junto con lo anterior, deberá adjuntar el comprobante del pago de la tarifa estipulada en el artículo $14 \mathrm{~b} .{ }^{17}$ Este escrito de solicitud será publicado en la Gaceta, notificando al solicitante del registro para que dé una contestación o hacer manifestaciones que a su derecho convenga. Una vez que el IMPI reciba ambos ocursos legales, abrirá una etapa de alegatos para que en un plazo de dos días

14 Disponible en: https://siga.impi.gob.mx/newSIGA/content/common/principal.jsf.

15 Disponible en: https://www.gob.mx/cms/uploads/attachment/file/235543/ Ley_de_Propiedad_Industrial_01-06_2016.pdf.

16 Nueva ley publicada en el Diario Oficial de la Federación el 1 de julio de 2020. Los artículos 5 fracciones VI, VII, VIII, 393, 394, 396 fracción I, 397, 398 y 400 de esta ley, publicada en el DOF 01/07/2020, entró en vigor el 5 de noviembre de 2021 de conformidad con lo dispuesto en el artículo Décimo Séptimo Transitorio de la propia ley.

17 Por el estudio de la oposición a una solicitud de registro de marca, aviso o nombre comercial, por cada uno, con un valor de \$3,704.09 MXN más IVA. 
hábiles ambas partes puedan adjuntar las pruebas correspondientes que respalden sus dichos. Por último, el IMPI continuará con el examen de fondo tomando en cuentan los argumentos de ambas partes, para finalmente emitir una resolución. Esta puede ser a favor del oponente (citar un oficio de similitudes o de impedimento legal al usuario solicitante) o a favor del usuario solicitante (es decir, no tomar en cuenta los argumentos expuestos por el oponente). Pero los examinadores en el IMPI no hacen manifestaciones a los argumentos expuestos por ambas partes, sino al final, es decir, al consumar todo el proceso de examinación de la solicitud de marca objeto del Sistema de Oposición.

Actualmente, con la implementación del Sistema de Oposición al registro de marcas, el IMPI podrá obtener información útil para determinar la viabilidad del registro solicitado, por lo que tendrá más elementos para ejercer su facultad de determinar si una solicitud de registro incurre en algunas de las prohibiciones previstas en la Ley Federal de Protección a la Propiedad Industrial.

Es así que podemos entender dos grandes aspectos: el principal es hacer más eficiente y eficaz el procedimiento de registro de marcas, brindando mayor seguridad jurídica a los usuarios, o sea, proporcionarle al Instituto Mexicano de la Propiedad Industrial los elementos necesarios para que cumpla sus facultades como autoridad competente en materia de Registro de Marcas; y por último, pero no menos apreciado, posicionar a México en el plano internacional por medio del Instituto Mexicano de la Propiedad Industrial como un país que adecua de manera correcta los estándares marcados por la Organización Mundial de la Propiedad Intelectual (OMPI), ${ }^{18}$ es así como se menciona en la siguiente nota:

El sistema de oposición de marcas se ha reforzado con la inclusión de la posibilidad de que las partes (el solicitante y el oponente) presenten pruebas y argumentos que tendrá en cuenta el IMPI

18 La Organización Mundial de la Propiedad Intelectual (OMPI) es un organismo especializado del Sistema de Naciones Unidas, creado en 1967 con la firma de la Convención de Estocolmo. Está dedicada a fomentar el uso y la protección de las obras del intelecto humano. 
a la hora de resolver la oposición. La falta de contestación a una oposición no supone automáticamente que se considere que se ha abandonado la solicitud, por lo que el IMPI continuará con su examen habitual. Las oposiciones presentadas seguirán publicándose en el "Gaceta de la Propiedad Industrial". Sin embargo, en virtud del Sistema de Madrid, a partir de ahora el IMPI emitirá denegaciones provisionales de los registros internacionales que susciten oposiciones. Los plazos y las condiciones para presentar y contestar una oposición no han sido alterados por las modificaciones. El Instituto dictará la resolución que corresponda a las oposiciones recibidas, expresando los fundamentos jurídicos de su resolución. (Organización Mundial de la Propiedad Intelectual, 2018, p. 3)

Por lo tanto, podemos comprender que con el Sistema de Oposición al registro de marcas los oponentes y/o solicitantes no van a sustituir las facultades de los examinadores del IMPI, sino que, por el contrario, se los apoyará proporcionándoles los elementos necesarios para que aporten fundamentos y argumentos al criterio del examinador para que, de esta forma, puedan emitir un razonamiento amplio respecto al estudio de la solicitud de marca correspondiente, lo que quiere decir que siempre estará en manos del examinador, de acuerdo a su pericia, negar y otorgar un registro de marca.

\section{Ventajas y desventajas del sistema de oposición de Argentina y México}

El Branding no es sólo una estrategia, es también una forma de vida, una idea, la marca es en realidad el liderazgo.

Onyi Anyado ${ }^{19}$

Con la implementación del Sistema de Oposición en el Procedimiento Administrativo para el Registro de Marcas en los Estados Unidos Mexicanos, se estiman una serie de ventajas en comparación

19 Disponible en: https://astuciaempresarial.com/que-es-el-co-branding/. 
con un procedimiento administrativo de nulidad o cancelación de registro de marca. Se ellas se desprenden las siguientes:

1) La solicitud de oposición a una marca en trámite se entiende como un proceso contencioso administrativo, es muy sencillo y expedito, aunque no muy económico (para el usuario oponente, ya que para que se dé a trámite se tiene que pagar la tarifa relacionada con el artículo 14b: "Por el estudio de la oposición a una solicitud de registro de marca, aviso o nombre comercial, por cada uno; con un valor de $\$ 3,704.09$ MXN más IVA", ${ }^{20}$ pero el usuario solicitante de la marca no tiene que cubrir ninguna tarifa para dar contestación a dicha petición).

2) Cualquier usuario o tercero puede solicitar el inicio del procedimiento de oposición, siempre y cuando lo realice por escrito, dentro del plazo legal de treinta días corridos y que cubra el pago de la tarifa correspondiente; no hay necesidad de que el usuario oponente acredite interés jurídico o legítimo en el asunto, como puede suceder en otros procedimientos administrativos en algunos países donde sí se tiene que acreditar para que sea procedente o no la solicitud.

3) Con la solicitud del sistema de oposición en el procedimiento administrativo para el registro de marcas, dicha petición genera una colaboración con el examinador del IMPI para darle información y pruebas para que, en el caso de una solicitud de marca que se encuentra en trámite, se pueda encuadrar en los supuestos de no registrabilidad de conformidad con el artículo 173 de la Ley Federal de Protección a la Propiedad Industrial; ya que, como sabemos, en el aspecto humano que conforma el criterio y usanza de cada examinador en el IMPI (o de cualquier otro ser humano) puede provocar algunas omisiones o errores en sus análisis, por ello, el sistema de oposición es una herramienta muy útil para poder subsanar dichos errores.

4) La ventaja de la implementación de la Ley Federal de Protección a la Propiedad Industrial es que promete -en relación con el procedimiento de oposición en el sistema mexicano- y vincula con el procedimiento de nulidad que la marca objeto de la oposición sea concedida. Específicamente, sobre la no posibilidad de levantar un procedimiento administrativo de nulidad con los mismos argu-

20 Impuesto al Valor Agregado. 
mentos presentados en la oposición. Con ello, brinda la posibilidad y evita que el IMPI se pronuncie de nuevo sobre un procedimiento examinado con antelación. Por este motivo, resulta de manera positiva en la implementación de recursos humanos, económicos y tiempo de manera efectiva.

5) El plazo de contestación del IMPI para emitir una resolución o dictamen en relación con la petición de un procedimiento de oposición a una solicitud de marca en trámite es de aproximadamente cinco a siete meses, es decir, lo que lleva todo el Examen de Fondo para determinar una contestación. Este plazo podrá considerarse extendido, pero, en comparación con otros países, es una réplica alígera (aunque no muchas veces eficiente). Tal es el caso del expediente de marca número 2483957, en el que la Coordinación Departamental de Examen de Marcas "B" del IMPI admitió la solicitud al estudio de la oposición a dicho expediente de registro de marca en representación de la persona moral MARY KAY INC. como oponente, por lo que la autoridad emitió el oficio de impedimento legal por existir similitud en grado de confusión entre el signo distintivo MK MAGICKUR (y diseño) y la marca registrada MARY KAY. Es decir que la autoridad administrativa tomó en cuenta los argumentos y pruebas del oponente para emitir dicho oficio, como se observa en la petición del usuario oponente. ${ }^{21}$

En cuando a las desventajas, se pueden encontrar las siguientes:

Las principales inquietudes de los usuarios oponentes son a) ¿por qué se tiene que cubrir una tarifa por la solicitud de una oposición?, y b) ¿por qué la tarifa es superior a la del estudio por la examinación de una solicitud nacional para el registro de una marca, aviso comercial o nombre comercial hasta la conclusión del trámite o, en su caso, la expedición del título?

En el primer aspecto, en el año 2019 el máximo tribunal constitucional del país y cabeza del Poder Judicial de la Federación, la Suprema Corte de Justicia de la Nación, resolvió por medio de su $2^{\text {a }}$ Sala que la base legislativa que da sustento a la oposición de registro marcario se entiende como un servicio público de la Federa-

21 Disponible en: http://acervomarcas.impi.gob.mx/marcanet/UCMServlet?info=M3wyMDIxMDQ4MzQwOXwxfDIwMjEwNDgzNDA5. 
ción (ejercido a través del IMPI), y que con su ayuda coopera para lograr la prestación de dicho servicio, por lo tanto, se deben asumir costos de operación administrativa que garanticen su continuidad y mejores condiciones para ofrecerlo. Por este motivo, es necesario el cobro de una tarifa para la realización de la gestión correspondiente de los derechos fundamentales que tutela el sistema de protección de propiedad industrial, por ello, debe ser proporcional, toda vez que, al implementar una tarifa, genera un ahorro en los canales y procesos ante las autoridades administrativas, ya que se considera al sistema de oposición en el procedimiento administrativo para el registro de marcas como un procedimiento cuasi contencioso, es decir, que para accionarlo es necesario cubrir el pago de la tarifa correspondiente, además de generar la petición por escrito y dentro plazo legal estipulado en la ley en materia.

Sirve a lo anterior la siguiente tesis:

\section{Registro Digital: 2021245}

Localización: 10a. Época, 2a. Sala, Gaceta del S.J.F., Libro 73, Diciembre de 2019, Tomo I, p. 567, [A], Constitucional.

Número de tesis: 2a. LXXV/2019 (10a.)

PROPIEDAD INDUSTRIAL. EL SEGUNDO PÁRRAFO DEL ARTÍCULO 120 DE LA LEY RELATIVA, QUE PREVÉ EL PAGO DE LA TARIFA COMO REQUISITO DE ACCESO A LA OPOSICIÓN DE REGISTRO MARCARIO, SE AJUSTA A LOS PRINCIPIOS DE RAZONABILIDAD Y PROPORCIONALIDAD JURÍDICA.

La medida legislativa de oposición de registro marcario es un servicio que persigue como finalidades constitucionalmente legítimas la certeza, calidad, eficiencia y celeridad del indicado registro, así como la protección del colectivo de consumidores, previstas en los artículos 14, 16 y 28 de la Constitución Política de los Estados Unidos Mexicanos. Además, es adecuada porque impulsa la participación cívica desde la cooperación responsable y evita que se promuevan oposiciones frívolas, improcedentes o superfluas que no sólo entorpecen la contraprestación del servicio mismo, al congestionar el aparato administrativo, sino que también impactan en el desarrollo económico, al retrasar el registro marcario; o bien, al 
grupo de consumidores, al impedirles el acceso a productos en un esquema más ágil. Asimismo, es necesaria porque se incentiva la cooperación responsable ya que para lograr la prestación del servicio se deben asumir costos de operación administrativa que garanticen su continuidad y mejores condiciones para ofrecerlo. Es razonable, en tanto protege en mayor intensidad la relación de los derechos fundamentales conexos que tutela el sistema de protección de propiedad industrial; y es proporcional, toda vez que al imponer una tarifa, protege otros derechos fundamentales, además de generar un ahorro en los canales y procesos ante las autoridades administrativas.

También es importante mencionar que, al accionar, el derecho de oposición marcario puede provocar una demora en los plazos de repuesta de la autoridad administrativa, es decir que dar inicio al procedimiento administrativo de oposición a una solicitud de marca nueva puede generarle un trabajo adicional al examinador, ya que no solo tendrá que revisar la solicitud de marca entrante, sino también la petición del tercero oponente incluyendo sus pruebas y la etapa de alegatos correspondientes. De por sí el plazo de estudio que se toman en la oficina de marcas es de aproximadamente tres a seis meses para conceder o citar un oficio de impedimento legal, y con la solicitud de oposición puede ampliarse ese plazo hasta dieciocho meses. ${ }^{22}$

Otra situación es que, durante el sistema de oposición en el procedimiento administrativo para el registro de marcas, el examinador del IMPI no hace comentarios de fondo a la petición del usuario oponente. En ese aspecto, solamente se limita a manifestar si la solicitud lleva adjuntada el pago de la tarifa correspondiente, y en el supuesto de que el usuario oponente sea una persona moral, se deberá acreditar la personalidad del mandante o representante legal, pero en temas de fondo no hace ningún tipo de exposición o comentarios. Solamente cuando termina el examen de fondo de la marca objeto de la oposición es cuando se emite alguna vista de impedimento a registro por algunas de las causales de no registrabilidad, es decir que la autoridad, al momento que se pronuncia con la concesión de la

22 Disponible en: https://acervomarcas.impi.gob.mx:8181/marcanet/UCMServlet?info=M3wyMDIxMDQ3MTA2NXwxfDIwMjEwNDcxMDY1. 
marca o con alguna vista u oficio de impedimento legal a registro, es cuando realiza los comentarios correspondientes. Por lo que durante el plazo que dura el procedimiento de registro de marca -que es entre cinco y siete meses (aproximadamente) - deja en suspenso a las partes involucradas.

En el caso del sistema de oposición de marcas de Argentina, se aprecian las siguientes ventajas a partir de la implementación en su regulación de la última adhesión de esta figura jurídica, en comparación con el sistema que se implementa en México:

En el anterior sistema de oposición, si el solicitante no alcanzaba un acuerdo amigable con el oponente, con o sin mediación previa se debía recurrir a la acción de cese de oposición (junto con los costos de los aranceles correspondientes, así como asociado con la mediación previa obligatoria), por lo que, con esta medida, el usuario solicitante tendría que gastar más dinero, así como demorar más el proceso de registro, ya que si en este "conflicto" no se llegaba a un arreglo amigable entre las partes, se habría gastado más dinero al recurrir a una acción judicial ante la Cámara Comercial Federal.

Asimismo, está el aspecto de mantener la conciliación como una mediación obligatoria o cualquier medio de resolución de controversias, tal como es el espíritu de la ley en Argentina. En cualquier parte de sus procedimientos, la autoridad competente escucha los conflictos de las partes para así evitar cualquier desgaste y conservación en la economía procesal de las instituciones, y no es excepción el caso del sistema de oposición de marcas, ya que en una parte de su procedimiento se da apertura a una conciliación con la notificación fehaciente de la oposición por parte del INPI. A partir de allí, se abre un plazo de tres meses para arribar al acuerdo voluntario intentando el levantamiento de la oposición. En caso de que la autoridad se enfrente a la inactividad de la contraparte y a su marcado desinterés por arribar a dicho acuerdo, el plazo queda vencido. Ahora bien, una vez que dicho período queda vedado, el INPI debe intimar de manera fehaciente a la parte oponente para que esta ratifique dicha oposición en un plazo de quince días hábiles. En caso de no mantenerla, la oposición queda descartada en calidad de "llamado de atención" y la solicitud de registro avanza a la última etapa: el estudio en la División de Análisis de Fondo. 
Como lo mencionamos en el párrafo que antecede, el usuario oponente a una solicitud de marca debe ratificarla, es decir que, después del plazo legal de la petición, tiene que confirmar su postulación con el complemento de un segundo pago de tasas oficiales y, además, profundizar en sus argumentos de oposición a dicha solicitud. Esto provoca una mayor certeza y seguridad jurídica al proceso, ya que, como tal, no cualquier persona puede activar el sistema de oposición marcario en la Argentina, sino aquella que realmente tenga interés en iniciar este procedimiento, ya que tendrá que cargar con un costo económico considerable y, por supuesto, un mayor análisis jurídico para plantear los argumentos suficientes con el fin de desalentar la solicitud de marca que se encuentra en conflicto, por lo que esta medida desalienta las oposiciones infundadas de los terceros.

A su vez, la presentación de la defensa de la oposición no tiene costo para el usuario solicitante de la marca objeto de la oposición, por lo que se genera una forma más expedita de dicha defensa en la sede administrativa contra la oposición.

En cuanto a las desventajas, se encuentran las siguientes:

En el momento en que se inicia el sistema de oposición, las distintas etapas del procedimiento quedan habilitadas, dado que el INPI se encarga de notificar la apertura de la etapa siguiente. Esto provoca que se ralentice muchísimo el proceso de estudio de la solicitud de marca, ya que la autoridad administrativa es considerablemente deficiente para hacer cumplir con estas notificaciones, por lo que podemos afirmar que desde que el actual sistema se instituyó hasta el día de la fecha persisten retrasos considerables en las notificaciones de las diversas instancias del proceso, lo cual provoca que el sistema de oposición se desvirtúe porque el INPI termina demorando más en dar seguimiento al proceso de oposición para dar una resolución que como estaba implementando anteriormente. Debido a esto, y como recomendación ante esta situación, el INPI debe optimizar en sus operaciones internas la implementación de sus notificaciones para que estas situaciones no pasen, o inclusive se puede emplear un sistema automatizado para emitir providencias simples para así notificar a las partes por medio de una máquina, siempre y cuando se cumplan con los requisitos mínimos de forma.

A continuación, se muestra un cuadro comparativo-reflexivo de 


\section{las etapas del proceso del Sistema de Oposición al registro de marcas de México y Argentina:}

\begin{tabular}{|c|c|c|}
\hline País & \multirow{2}{*}{ México (IMPI) } & \multirow{2}{*}{ Argentina (INPI) } \\
\hline Fase & & \\
\hline $\begin{array}{l}\text { Publicación } \\
\text { solicitud de } \\
\text { marca }\end{array}$ & $\begin{array}{l}10 \text { días hábiles siguientes a su } \\
\text { presentación. }\end{array}$ & $\begin{array}{l}\text { En un plazo inferior promedio } \\
\text { entre } 4 \text { y } 5 \text { meses después de su } \\
\text { presentación. }\end{array}$ \\
\hline $\begin{array}{l}\text { Costo de la } \\
\text { solicitud de } \\
\text { oposición }\end{array}$ & $\begin{array}{l}\text { \$3704.09 pesos mexicanos (más } \\
\text { IVA). } \\
\text { Mantener oposición: segundo } \\
\text { pago de arancel. }\end{array}$ & Inicial: arancel correspondiente. \\
\hline Oponente & $\begin{array}{l}\text { Cualquier persona, sin necesidad } \\
\text { de profundizar en argumentos o } \\
\text { fundamentos legales para opon- } \\
\text { erse al solicitante y previo pago de } \\
\text { los aprovechamientos correspon- } \\
\text { dientes. }\end{array}$ & $\begin{array}{l}\text { Cualquier persona. En la primera } \\
\text { etapa solo será necesario que } \\
\text { el oponente argumente o cite el } \\
\text { impedimento legal al registro de } \\
\text { forma breve a la solicitud de la } \\
\text { marca que se considere similar a la } \\
\text { suya (o el impedimento correspon- } \\
\text { diente), previo pago de los dere- } \\
\text { chos al Gobierno correspondiente. } \\
\text { En una segunda etapa, el oponen- } \\
\text { te tendrá que abonar un segundo } \\
\text { pago de derechos (mucho mayor } \\
\text { al primero) y ahí mismo deberá } \\
\text { adjuntar un escrito fundado, mo- } \\
\text { tivado con las pruebas pertinen- } \\
\text { tes; asimismo, puede ampliar su } \\
\text { fundamento para mantener dicha } \\
\text { oposición. }\end{array}$ \\
\hline $\begin{array}{l}\text { Plazo para } \\
\text { oponerse }\end{array}$ & $\begin{array}{l}\text { Dentro de los } 30 \text { días corridos } \\
\text { contados a partir del día hábil } \\
\text { siguiente de su publicación en la } \\
\text { Gaceta. }\end{array}$ & $\begin{array}{l}\text { Dentro de los } 30 \text { días corridos } \\
\text { contados a partir del día hábil } \\
\text { siguiente de su publicación en el } \\
\text { Boletín. } \\
\text { También se puede ingresar la } \\
\text { solicitud de oposición fuera de ese } \\
\text { plazo, pero no es vinculante para } \\
\text { el INPI si toman en cuenta o no } \\
\text { los argumentos vertidos en dicha } \\
\text { petición. }\end{array}$ \\
\hline $\begin{array}{l}\text { Contestación de } \\
\text { la oposición }\end{array}$ & $\begin{array}{l}\text { El solicitante puede realizar declara } \\
\text { como adjuntar las pruebas necesari } \\
\text { dentro del plazo legal para admitirs } \\
\text { tarifa o pago de aprovechamientos } \\
\text { IMPI emiten una vista de oposición, } \\
\text { Gaceta, respectivamente. Esta es la }\end{array}$ & $\begin{array}{l}\text { iones en contra a la oposición, así } \\
\text { Is siempre y cuando se promueva } \\
\text {. Asimismo, no se requiere ninguna } \\
\text { ara dar contestación. El INPI o el } \\
\text { que se publica en el Boletín o en la } \\
\text { notificación de la oposición. }\end{array}$ \\
\hline
\end{tabular}




\section{Revista Iberoamericana de la Propiedad Intelectual}

\begin{tabular}{|c|c|c|}
\hline Conciliación & $\begin{array}{l}\text { No aplica, ya que no está im- } \\
\text { plementado de forma oficial un } \\
\text { método alternativo de solución de } \\
\text { controversias. }\end{array}$ & $\begin{array}{l}\text { Al momento de notificar al usuario } \\
\text { solicitante del traslado del derecho } \\
\text { de oposición del tercero oponente, } \\
\text { se da apertura a un plazo de tres } \\
\text { meses para que las partes alca- } \\
\text { ncen un acuerdo por vía de Medi- } \\
\text { os Alternativos de Resolución de } \\
\text { Conflictos, ya que el espíritu gen- } \\
\text { eral de la legislación de Argentina } \\
\text { siempre es tender a la resolución } \\
\text { amigable de controversias y, por } \\
\text { ende, también tratar de descom- } \\
\text { primir la labor de las autoridades. }\end{array}$ \\
\hline $\begin{array}{l}\text { Manifestación } \\
\text { de la autoridad } \\
\text { administrativa }\end{array}$ & $\begin{array}{l}\text { El Instituto Mexicano de la Propie- } \\
\text { dad Industrial, a través de sus } \\
\text { examinadores, no realiza ninguna } \\
\text { declaración respecto a la solicitud } \\
\text { de la oposición o, en su defecto, } \\
\text { de la contestación de esta. Al final } \\
\text { solo contemplará los elementos } \\
\text { aportados por el oponente y el } \\
\text { solicitante para que este último } \\
\text { pueda emitir una resolución final } \\
\text { al momento de analizar la solicitud } \\
\text { en examen de fondo. }\end{array}$ & $\begin{array}{l}\text { El Instituto Nacional de Propiedad } \\
\text { Industrial, a través de sus exam- } \\
\text { inadores, podrá decidir quién tiene } \\
\text { mejores argumentos: si el oponen- } \\
\text { te o el solicitante, y, de esta forma, } \\
\text { emite un dictamen. En este, para } \\
\text { lograr la resolución, se consideran } \\
\text { los escritos de ambas partes, las } \\
\text { pruebas ofrecidas y las pruebas } \\
\text { elaboradas. }\end{array}$ \\
\hline $\begin{array}{l}\text { Examen de forma } \\
\text { y fondo }\end{array}$ & $\begin{array}{l}\text { El examen de forma se hace den- } \\
\text { tro de los primero dos meses de } \\
\text { haberse presentado la solicitud de } \\
\text { marca. De no existir algún requer- } \\
\text { imiento de forma, se pasa al exam- } \\
\text { en de fondo y se estudia para su } \\
\text { otorgamiento, por lo que todo el } \\
\text { procedimiento de registro podría } \\
\text { dilatarse entre cinco y seis meses }\end{array}$ & $\begin{array}{l}\text { El examen de forma se gestiona } \\
\text { antes de su publicación en el Bo- } \\
\text { letín, ya que no publica la solicitud } \\
\text { si no cumple con los requisitos for- } \\
\text { males. Después se publica y, den- } \\
\text { tro de los treinta días de publicada } \\
\text { la solicitud, se pueden presentar } \\
\text { las oposiciones. El plazo normal de } \\
\text { concesión, sin oposiciones ni vistas } \\
\text { administrativas, es de doce meses. }\end{array}$ \\
\hline Resolución & \multicolumn{2}{|c|}{$\begin{array}{l}\text { Negativa, otorgamiento y expedición del título de marca según sea el } \\
\text { caso; en el supuesto de que la autoridad otorgue el registro de marca, el } \\
\text { título se emitirá de manera automática y se publicará en la Gaceta y/o } \\
\text { Boletín en un plazo de entre veinte y treinta días corrido después de su } \\
\text { publicación. }\end{array}$} \\
\hline
\end{tabular}




\section{Conclusión}

Una marca no es un producto, es la fuente del producto, su significado y su dirección, definen su identidad en el tiempo y el espacio.

Jean-Noel Kapferer ${ }^{23}$

En términos generales, los signos distintivos que se protegen por medio de una marca o de un aviso comercial son elementos que aprovechan los empresarios o emprendedores para diferenciar sus productos y/o servicios de la misma especie entre sus competidores. Dichos bienes inmateriales son herramientas de singular importancia para su actividad comercial, pues con las marcas y avisos comerciales no solo ayudan a distinguirse de sus competidores directos, sino que también forman parte de la filosofía y de la imagen corporativa de la empresa, tan es así que integran parte del patrimonio de dichas instituciones.

Ahora bien, sabemos que la carga de trabajo de las autoridades administrativas ${ }^{24}$ es abundante y compleja. Además, dentro de la calidad humana de las personas que aprueban las solicitudes de marcas (examinadores) está en su comprender consumar alguno que otro error al otorgar registros marcarios que no debían concederse, ya sea por una similitud gráfica, fonética o simplemente por algún impedimento legal por considerarse genérica o que evoca la descripción de algún producto o del servicio que ampara dicha solicitud. Está claro que respalda esta afirmación la locución errare humanum est (errar es humano), por lo que se deduce que equivocarse es íntimo a la naturaleza humana, de ahí que la frase ha entrado en el argot común como aforismo con el que se busca mitigar un fallo, un error, siempre y cuando sea esporádico y no se repita. Como resultado, es natural que ocurra algún traspié de algún examinador, por ello la importancia de la implementación de un sistema de oposición al registro de marcas, ya que los propios solicitantes y oponentes serán coadyuvantes dentro del procedimiento, dado que le proporciona-

23 Disponible en: https://www.nordenestudio.es/tag/diseno-de-marca/.

24 Instituto Mexicano de la Propiedad Industrial, para México, e Instituto Nacional de Propiedad Industrial, para Argentina. 
rán al examinador los elementos necesarios para fortalecer su criterio al momento de estudiar una solicitud de marca, pero es importante que la autoridad siga teniendo tal potestad, ya que será a su consideración el valor que le dará a cada uno de los argumentos y pruebas presentados.

El INPI ha logrado implementar un sistema de oposición eficiente y eficaz después de la última reforma a la Ley 22362 de Marcas y Designaciones y las modificaciones introducidas por la Ley 27444 de Simplificación y Desburocratización para el Desarrollo Productivo. Asimismo, eliminó de su sistema de oposición la parte tan insidiosa y conflictiva de la etapa de conciliación, ya que el solicitante que recibía la oposición debía ocuparse firmemente de lograr un acuerdo amigable con el oponente y su agente o representante letrado, en donde muchas veces se obligaba a firmar acuerdos de no competencia para determinados productos o servicios de interés del oponente para que negociaran el levantamiento de la oposición otorgándole un acuerdo de no competencia. Si lo conseguía, valía la pena toda la negociación, pero si no lograba un acuerdo amigable con el oponente, incluida la instancia de mediación previa y obligatoria, el solicitante podía verse obligado a iniciar un juicio de cese de oposición, buscar a un juez que dictamine que la oposición era infundada y obligar al INPI a concederle la marca al solicitante, para lo cual se invertía más de tres años y mucho dinero en honorarios de abogados para el menesteroso solicitante. Pero ahora, con dichas adhesiones a la legislación que nos compete, se logra esa eficiencia en el proceso del sistema de oposición, ya que el oponente ahora tendrá que pensar dos veces si desea oponerse. El examinador podrá hacer manifestación después de revisar la solicitud del oponente y la contestación del solicitante, por lo que dicho proceso se podrá subsanar más rápido y sin necesidad de hacer una mayor inversión, como se venía haciendo con anterioridad. También es importante mencionar, en especial para el caso argentino, que la solicitud de marca que logró superar con éxito un proceso de oposición resultará fortalecida. Además, salvo arbitrariedad manifiesta por parte de la autoridad administrativa, los tribunales en general son permeables a aceptar la decisión o resolución del INPI, ya que consideran que es un organismo especializado en la materia. 
En el caso de México, el sistema de oposición podría verse fortalecido por el agregado de la facilitación de las partes para presentar pruebas y argumentos que tendrán en cuenta como elementos a considerar para que el examinador del IMPI emita una resolución respecto al estudio de fondo de dicha solicitud. También podemos entender que la omisión de una contestación de una solicitud de oposición (para el solicitante) dentro del plazo legal no puede considerarse como que el solicitante ha abandonado su solicitud, simplemente perdió su oportunidad de alegar o de contradecir el argumento del oponente, perdió la oportunidad de brindarle un segundo enfoque al examinador, por lo que se entiende que el procedimiento de registro de marcas seguirá su curso con normalidad, pero ahora el examinador tendrá más elementos para dictar una resolución adecuada a la solicitud de marca en particular, manifestándose con los argumentos y fundamentos jurídicos adecuados.

Lo que se puede concluir haciendo un análisis comparativo de los sistemas de oposición que implementan el IMPI y el INPI sería que en México hay un sistema gris, incoloro, mórbido principalmente porque la autoridad en ningún momento plasma una manifestación respecto a la solicitud y a la contestación de la oposición, como resultado de que no cumple el objetivo planteado en el decreto de la reforma implementada en la Ley Federal de Protección a la Propiedad Industrial, pues el oponente no puede tener respuesta a su oposición sino una vez que concluya el trámite de registro (entre 5 y 6 meses aproximadamente), por ende, lo coloca en un estado de incertidumbre jurídica, pues al ser la oposición parte del procedimiento administrativo de registro de marca, la autoridad debería dar una respuesta o comentarios después de la solicitud de la oposición y no solo cuando llegue al examen de fondo. Lo que sí realiza son intervenciones, en el sentido de que si el usuario que promueve la solicitud de oposición se encuentra autorizado en el expediente para gestionar dicha petición, pero como tal no hace manifestación o emite algún comentario en relación a que si la oposición es admitida o no; en el mismo supuesto se encuentra el usuario solicitante: si en el momento oportuno realiza la contestación a la oposición, la autoridad tampoco expresa alguna respuesta o declaración de fondo.

En efecto, se entiende que la autoridad como tal no se encuentra 
obligada a atender los elementos ofrecidos por las partes ni de valorarlos en esa misma etapa procesal al resolver si se procede o no con la solicitud de la oposición o, en su defecto, si la contestación del solicitante es la idónea. Podría entenderse que con la implementación del sistema de oposición se dilataría un poco más todo el procedimiento de registro de marca, ya que requiere de un estudio más completo de lo que es, pero lo anterior no implicaría una negativa $\mathrm{u}$ omisión de alguna manifestación de fondo de la autoridad. En ese sentido podemos afirmar que el sistema de oposición implementado por el Instituto Nacional de la Propiedad Industrial de Argentina es más preciso y adecuado en comparación con el sistema que se implementa en los Estados Unidos Mexicanos.

\section{Bibliografía}

Enneccerus, L. (1935). Derecho civil. Parte General (Vol. 1). Bosh Casa Editorial.

Klein, N. (2002). No logo: el poder de las marcas. Paidós.

Organización Mundial de la Propiedad Intelectual. (2011). Comité permanente sobre el derecho de patentes ( $17^{\mathrm{a}} \mathrm{ed}$.).

Organización Mundial de la Propiedad Intelectual. (2018). Protocolo de Madrid relativo al Registro Internacional de Marcas. Aviso Informativo $\mathrm{N}^{\circ} 13$. https://www.wipo.int/edocs/madrdocs/es/2018/madrid_2018_13.pdf.

Otero Muñoz, I. (2011). Simetrías y Asimetrías entre el Derecho de Autor y la Propiedad Industrial ( $1^{\mathrm{a}}$ ed.). Porrúa. 
